\title{
Double Criteria Feeder-Selection Method for Single-Phase Ground Fault of Resonant Grounding System Based on Multi-State Components
}

\author{
Yixi Chen*, Rong Ju, Jie Xu, Gang Ma, Huaiyi Chen, Guchao Xu \\ School of Electrical \& Automation Engineering, Nanjing Normal University, Nanjing, China \\ *Corresponding author: nnucyx@163.com
}

\begin{abstract}
Resonant grounding system has been widely applied in low-voltage power systems all over the world. For the single-phase ground fault feeder-selection of resonant grounding system, the amplitude/phase comparison method of zero-sequence current which is used in traditional fault feeder-selection is not suitable to be used, due to the compensation action of arc suppression coil. In this paper, the electrical quantity changes after the single-phase ground fault of small current grounded system are analyzed firstly, therefore the reason why the amplitude/phase comparison method of zero-sequence current is not suitable to be used in resonant grounding system can be obtained. After that, based on zero-sequence current's multi-state components (transient component and steady component), a new fault feeder-selection method using double criteria is proposed, which not only can be applied in the singlephase ground fault of resonant grounding system but also has high reliability. At last, simulations based on MATLAB/Simulink are conducted to verify the validity of the method proposed in this paper.
\end{abstract}

Keywords: resonant grounding system, fault feeder-selection, single-phase ground fault, multi-state components

Cite This Article: Yixi Chen, Rong Ju, Jie Xu, Gang Ma, Huaiyi Chen, and Guchao Xu, "Double Criteria Feeder-Selection Method for Single-Phase Ground Fault of Resonant Grounding System Based on Multi-State Components." American Journal of Electrical and Electronic Engineering, vol. 5, no. 4 (2017): 144-151. doi: 10.12691/ajeee-5-4-4.

\section{Introduction}

The neutral non-direct grounded system, which is also called as small current grounded system, is widely used in $3 \sim 60 \mathrm{kV}$ distribution networks. It mainly includes neutral ungrounded system and arc suppression coil grounded neutral system (i.e. resonant grounding system) [1]. When the grounding current is large, the resonant grounding system can limit the magnitude of grounding current [2,3].

As one of the key technologies in distribution network, the fault feeder-selection technique can select and break off the faulty feeder in time, which is vital to the safe and reliable operation of distribution network [4]. The short circuit faults in distribution network mainly include three-phase short circuit faults, two-phase short circuit faults, two-phase ground short circuit faults, and single-phase ground faults. Where the occurrence probability of single-phase ground fault is far greater than others [5].

Therefore, it is very meaningful to research on the feeder-selection method for single-phase ground fault of resonant grounding system. However, due to the compensation action of arc suppression coil, the amplitude/phase comparison method of zero-sequence current which can be used in neutral ungrounded system is not suitable in resonant grounding system. Thus, it is very urgent to derive a new feeder-selection method which is suitable to the single-phase ground fault of resonant grounding system [6]. At present, the academic circles have already done some researches on it, however, most of the current methods are based on single criterion $[7,8]$, and the reliability needs to be improved.

Given this situation, based on zero-sequence current's multi-state components (transient component and steady component), a double criteria feeder-selection method, which not only can be applied in the single-phase ground fault of resonant grounding system but also has high reliability is proposed in this paper. The remaining of this paper is structured as follows: In Section 2, the electrical quantity changes after the single-phase ground fault of small current grounded system are analyzed, and the reason why the amplitude/phase comparison method of zero-sequence current is not suitable to be used in resonant grounding system is summarized. In Section 3, in view of the above analysis results, the double criteria feeder-selection method is designed with the aid of wavelet decomposition. Simulations based on MATLAB/Simulink are conducted to verify the validity of the method proposed in this paper in Section 4. The whole text is summed up in Section 5.

\section{Electrical Quantity Analysis of Small Current Grounded System}

The electrical quantity changes after the single-phase ground fault of small current grounded system are analyzed in this section, and the reason why the amplitude/phase comparison method of zero-sequence 
current is not suitable to be used in resonant grounding system will be summarized.

\subsection{Electrical Quantity Analysis of Neutral Ungrounded System}

Neutral ungrounded system means the system in which the neutral is insulated to ground, as shown in Figure 1, where the distributed capacitance on the feeder is treated as centralized capacitors; the single-phase ground fault point is set in the phase A of feeder $\mathrm{n}$; $I_{\mathrm{f}}$ is the fault current in the faulty feeder's faulty phase.

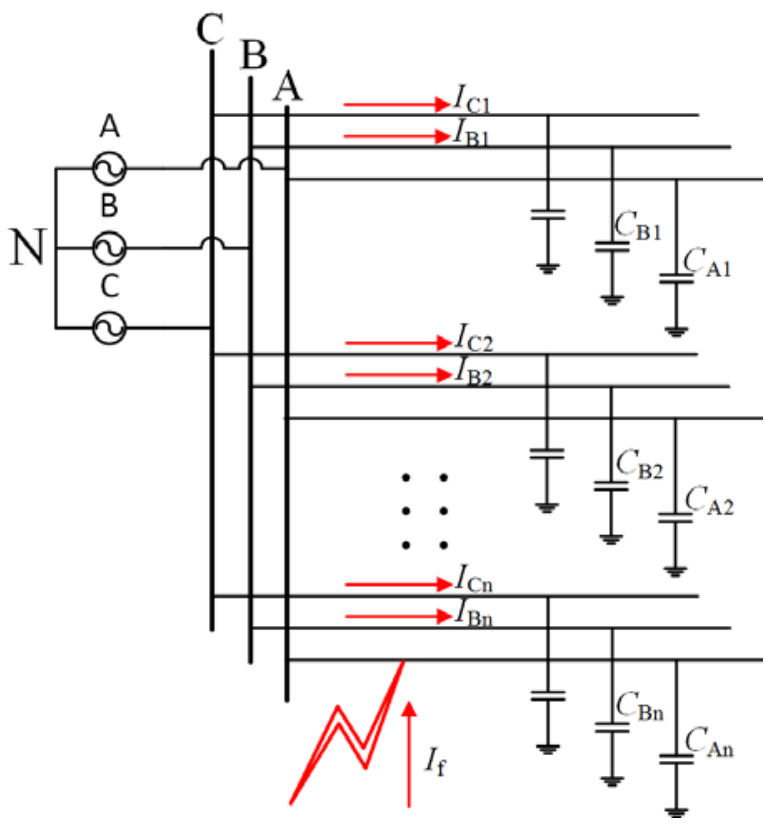

Figure 1. The schematic diagram of the single-phase ground fault in neutral ungrounded system

According to Figure 1, the zero-sequence current of non-fault feeders can be expressed as:

$$
I_{0 i}=\frac{1}{3}\left(I_{\mathrm{Bi}}+I_{\mathrm{Ci}}\right)
$$

where $i$ is the feeder number; $I_{\mathrm{B} i}$ is the capacitive current in phase $\mathrm{B}$ of non-fault feeders; $I_{\mathrm{C} i}$ is the capacitive current in phase $\mathrm{C}$ of non-fault feeders.

The zero-sequence current of fault feeder can be expressed as:

$$
I_{0 \mathrm{n}}=\frac{1}{3}\left(I_{\mathrm{Bn}}+I_{\mathrm{Cn}}-I_{\mathrm{f}}\right)
$$

where $I_{\mathrm{f}}$ can be expressed as:

$$
I_{\mathrm{f}}=\sum_{i=1}^{\mathrm{n}}\left(I_{\mathrm{Bi}}+I_{\mathrm{Ci}}\right) .
$$

Therefore, substitute Eq.(3) into Eq.(2) and it can be obtained that:

$$
I_{0 \mathrm{n}}=-\frac{1}{3} \sum_{i=1}^{\mathrm{n}-1}\left(I_{\mathrm{Bi}}+I_{\mathrm{Ci}}\right) .
$$

Compare Eq.(1) and Eq.(4) and it can be found that, after a single-phase ground fault occurred in a neutral ungrounded system, the zero-sequence current phase of fault feeder has an opposite polarity with which of non-fault feeders, and the zero-sequence current magnitude of fault feeder is bigger than which of any other non-fault feeders. Therefore, using amplitude/phase comparison method of zero-sequence current to select the fault feeder in neutral ungrounded system is feasible.

\subsection{Electrical Quantity Analysis of Resonant Grounding System}

Resonant grounding system means the system in which the neutral is grounded with an arc suppression coil, as shown in Figure 2, where $I_{\mathrm{L}}$ is the compensating current provided by the arc suppression coil.

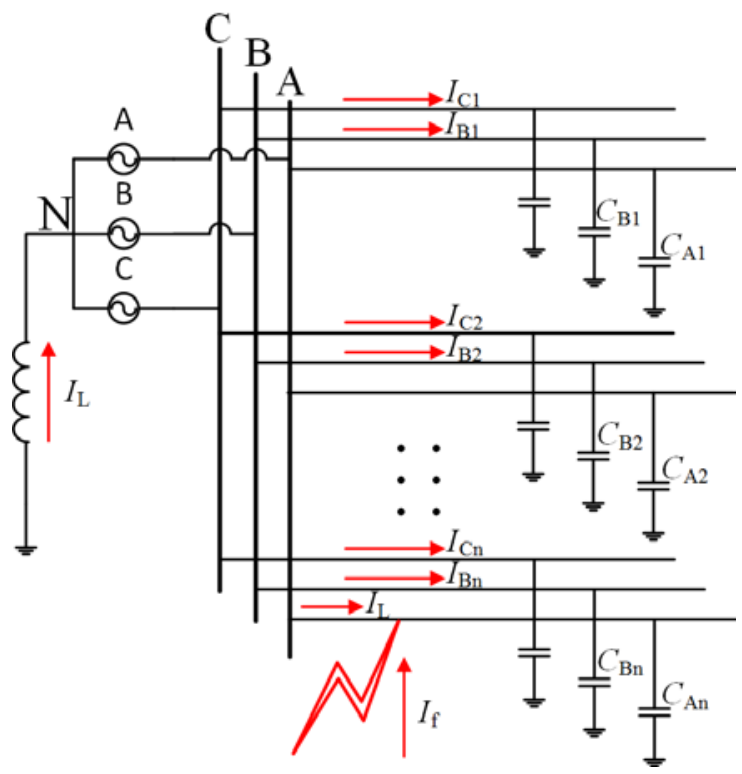

Figure 2. The schematic diagram of the single-phase ground fault in resonant grounding system

According to Figure 2, the zero-sequence current of non-fault feeders can still be expressed as Eq.(1), while the zero-sequence current of fault feeder should be changed as:

$$
\begin{aligned}
I_{0 \mathrm{n}} & =-\frac{1}{3}\left[\sum_{i=1}^{\mathrm{n}-1}\left(I_{\mathrm{Bi}}+I_{\mathrm{Ci}}\right)-I_{\mathrm{L}}\right] \\
& =-\frac{1}{3} \sum_{i=1}^{\mathrm{n}-1}\left(I_{\mathrm{Bi}}+I_{\mathrm{Ci}}\right)+\frac{1}{3} I_{\mathrm{L}} .
\end{aligned}
$$

As the resonant grounding system usually adopts over compensation mode, therefore it can be obtained that:

$$
I_{\mathrm{L}}>\sum_{i=1}^{\mathrm{n}-1}\left(I_{\mathrm{Bi}}+I_{\mathrm{Ci}}\right) .
$$

Substitute Eq.(6) into Eq.(5) and it can be found that, after a single-phase ground fault occurred in a resonant grounding system, the zero-sequence current phase of fault feeder does not have an opposite polarity with which of non-fault feeders, and the zero-sequence current magnitude of fault feeder may not be bigger than which of other non-fault feeders. Therefore, amplitude/phase comparison method of zero-sequence current is not 
suitable to be used in resonant grounding system. In order to select and break off the fault feeder correctly after a single-phase ground fault occurred in resonant grounding system, new feeder-selection method needs to be derived.

\section{The Double Criteria Fault Feeder-Selection Method Based on Multi-State Components}

The amplitude/phase comparison method of zero-sequence current is not suitable to be used in resonant grounding system, therefore a new feeder-selection method needs to be derived. The academic circles have already done some researches on it now, however, most of the current methods are based on single criterion, and the reliability needs to be improved.

With the aid of wavelet decomposition, which can decompose the transient component and steady component of a signal, this section proposed a double criteria feeder-selection method based on the multi-state components of feeders' zero-sequence current. The method proposed in this paper not only can be applied in the single-phase ground fault of resonant grounding system but also has high reliability.

\subsection{The Criterion Based on Zero- Sequence Current's Transient Component}

Due to the characteristics of time frequency focusing and zooming, the wavelet decomposition can effectively amplifies the weak transient component in the fault zerosequence current, therefore it is called as "Mathematical microscope” [9,10]. For the feeder-selection of singlephase ground fault in resonant grounding system, the wavelet decomposition can be used to extract the transient component of each feeder's zero-sequence current, and whose transient component has the opposite polarity and the biggest magnitude can be selected as the fault feeder.

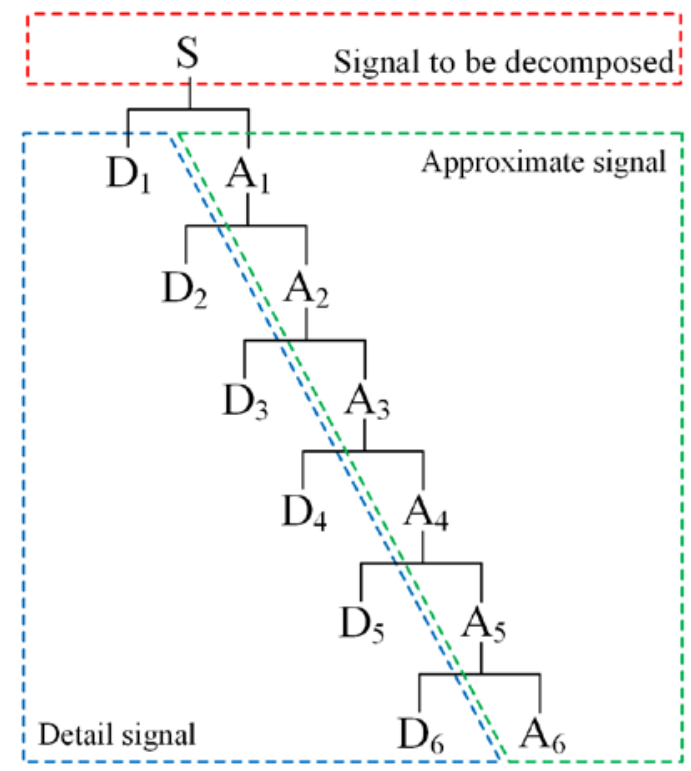

Figure 3. The schematic diagram of the 6-level wavelet decomposition process
In this paper, the zero-sequence current of each feeder is processed by the 6-level wavelet decomposition, as shown in Figure 3, where $\mathrm{S}$ is the signal to be decomposed. $\mathrm{S}$ is decomposed into 1-level detail signal $\mathrm{D}_{1}$ and 1-level approximate signal $\mathrm{A}_{1}$ after the first level wavelet decomposition; after the second level wavelet decomposition, $\mathrm{S}$ is decomposed into 1-level detail signal $\mathrm{D}_{1}$, 2-level detail signal $\mathrm{D}_{2}$, and 2-level approximate signal $\mathrm{A}_{2}$; analogously, $\mathrm{S}$ is decomposed into 1-level 6level detail signal $\mathrm{D}_{1} \sim \mathrm{D}_{6}$, and 6-level approximate signal $\mathrm{A}_{6}$ after the sixth level wavelet decomposition.

In Figure 3, the detail signal $\mathrm{D}_{i}$ represents the transient component extracted from $\mathrm{S}$, and bigger $i$ means purer transient component extracted. Therefore, the specific process of the transient component criterion established in this paper is:

(1) Measure the zero-sequence current of each feeder.

(2) Process the zero-sequence current by 6-level wavelet decomposition, and extract the 6-level detail signal $\mathrm{D}_{6}$.

(3) Compare the 6-level detail signal $\mathrm{D}_{6}$ of each feeder, if a $\mathrm{D}_{6}$ has the opposite polarity and the biggest magnitude, the corresponding feeder is selected as the fault feeder.

\subsection{The Criterion Based on Zero-Sequence Current's Steady Component}

When the resonant grounding system is in normal operation, the zero-sequence conductance of each feeder equals to the feeder leakage conductance $g$; the zerosequence susceptance of each feeder equals to the earth capacity $b$. Therefore, the zero-sequence admittance of each feeder can be expressed as:

$$
\dot{Y}_{0 i}=g_{i}+\mathrm{j} b_{i}
$$

where $i$ is the feeder number. As the feeder leakage conductance $g$ and the earth capacity $b$ are both greater than 0 when the system is in normal operation, the zerosequence admittance of each feeder can all be expressed as locations in the first quadrant as shown in Figure 4, therefore the admittance angle is smaller than $90^{\circ}$.

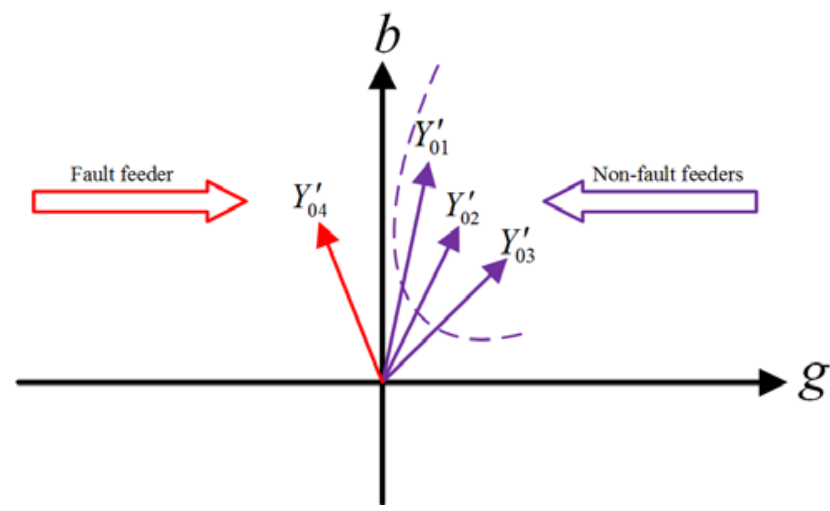

Figure 4. The schematic diagram of the zero-sequence admittance of feeders

When the resonant grounding system has a single-phase ground fault in a feeder, the zero-sequence admittance of non-fault feeders will not change, while the zero-sequence admittance of fault feeder will change to become the 
opposite number of all non-fault feeders' zero-sequence admittance plus the zero-sequence admittance of arc suppression coil, which can be expressed as:

$$
\dot{Y}_{0 k}=-\left(g_{\mathrm{L}}+\sum_{\substack{i=1 \\ i \neq k}}^{n} g_{i}\right)-\mathrm{j}\left(-b_{\mathrm{L}}+\sum_{\substack{i=1 \\ i \neq k}}^{n} b_{i}\right)
$$

where $k$ is the number of fault feeder; $g_{\mathrm{L}}$ and $b_{\mathrm{L}}$ are the zero-sequence conductance and zero-sequence susceptance of arc suppression coil respectively. As the zero-sequence conductance of arc suppression coil $g_{\mathrm{L}}$ and the zero-sequence conductance of non-fault feeder $g_{i}$ are both greater than 0 , the zero-sequence admittance of fault feeder can be expressed as locations in the second or third quadrant as shown in Figure 4, therefore the admittance angle is greater than $90^{\circ}$.

According to the above analysis, steady components of bus's zero-sequence voltage and feeders' zero-sequence current are extracted in this paper. The angle difference that zero-sequence current's steady component leads zero-sequence voltage's steady component is the admittance angle. Therefore, by comparing the leading angle with $90^{\circ}$, the fault feeder can be selected. Meanwhile, the approximate signal $\mathrm{A}_{i}$ obtained by wavelet decomposition represents the steady component extracted from $\mathrm{S}$, and bigger $i$ means purer steady component extracted. Therefore, the specific process of the steady component criterion established in this paper is:

(1) Measure the zero-sequence current of each feeder and the zero-sequence voltage of bus.

(2) Process the zero-sequence current and zero-sequence voltage by 6-level wavelet decomposition, and extract the 6-level approximate signal $\mathrm{A}_{6}$.

(3) Compute the angle difference that $A_{6}$ of each feeder's zero-sequence current leads $A_{6}$ of bus's zero-sequence voltage, if the angle difference is greater than $90^{\circ}$ and the corresponding feeder is selected as the fault feeder.

\subsection{Double Criteria Feeder-Selection Method}

The transient component criterion and steady component criterion have been established respectively in Section 3.1 and Section 3.2. However, if only one criterion is referred to select the fault feeder, the reliability of feeder-selection cannot meet the high requirement. Therefore, based on the two established criteria, this paper proposed a double criteria feeder-selection method, the specific process is shown in Figure 5.

As shown in Figure 5, after the single-phase ground fault of resonant grounding system, the zero-sequence current of each feeder and the zero-sequence voltage of bus are measured and decomposed by 6-level wavelet decomposition firstly. After that, based on 6-level detail signal $\mathrm{D}_{6}$ and 6-level approximate signal $\mathrm{A}_{6}$, the transient component criterion and steady component criterion are used respectively to select the fault feeder. If the two results are identical, break off the selected fault feeder; otherwise redone the process above until the results of two criteria are consistent with each other. Compared with the feeder-selection method based on only one criterion, the double criteria feeder-selection method can reduce the uncertainty and make the result more reliable.

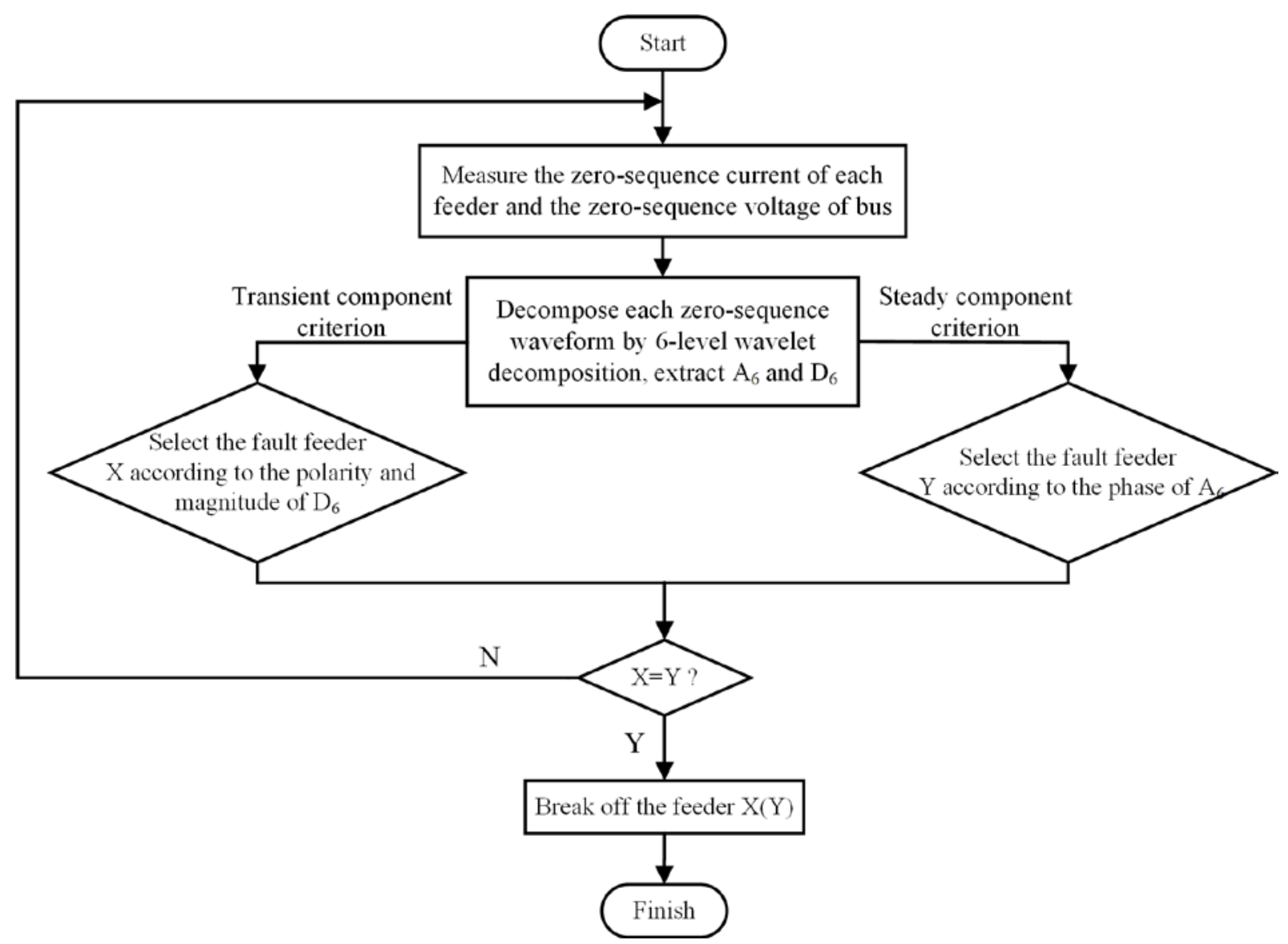

Figure 5. The flow chart of double criteria feeder-selection method 


\section{Case Studies}

Based on the 4-feeders resonant grounding system as shown in Figure 6, simulation model is established in this section by MATLAB/Simulink to verify the validity of the double criteria feeder-selection method proposed in this paper. The specific simulation parameters are shown in Table 1.

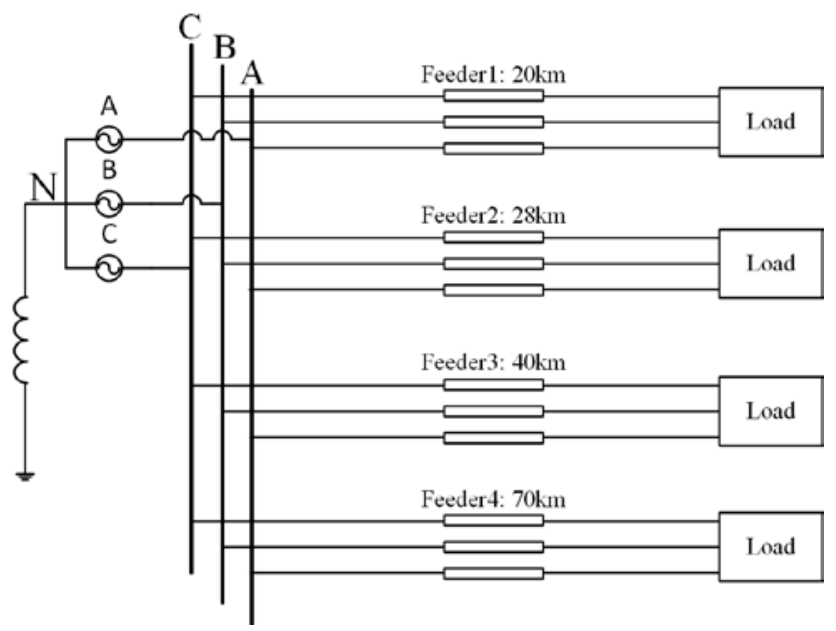

Figure 6. The schematic diagram of simulation model
Table 1. Specific Parameters of the Simulation Model

\begin{tabular}{ll}
\hline Voltage level & $10 \mathrm{kV}$ \\
\hline Positive-sequence feeder impedance per $\mathrm{km}$ & $0.01273+\mathrm{j} 0.9337 \mathrm{e}^{-3} \Omega$ \\
\hline Zero-sequence feeder impedance per $\mathrm{km}$ & $0.3864+\mathrm{j} 4.1264 \mathrm{e}^{-3} \Omega$ \\
\hline Positive-sequence distributed capacitance per $\mathrm{km}$ & $12.74 \mathrm{e}^{-9} \mathrm{~F}$ \\
\hline Zero-sequence distributed capacitance per $\mathrm{km}$ & $7.751 \mathrm{e}^{-9} \mathrm{~F}$ \\
\hline Load & $10 \mathrm{~kW}+100 \mathrm{Var}$ \\
\hline
\end{tabular}

\subsection{Case 1}

Choose a feeder to be the fault feeder of single-phase ground fault, the ground phase is phase $\mathrm{A}$, the fault time is $0.04 \mathrm{~s}$, the simulation duration is $0.2 \mathrm{~s}$, and the number of data sampling points is 5000. Decompose the zerosequence current of each feeder and the zero-sequence voltage of bus by wavelet decomposition, and extract the 6-level detail signal $\mathrm{D}_{6}$ and 6-level approximate signal $\mathrm{A}_{6}$.

The 6-level detail signal $\mathrm{D}_{6}$ of each feeder's zerosequence current is shown in Figure 7, while the 6-level approximate signal $\mathrm{A}_{6}$ of each feeder's zero-sequence current and the bus's zero-sequence voltage is shown in Figure 8.

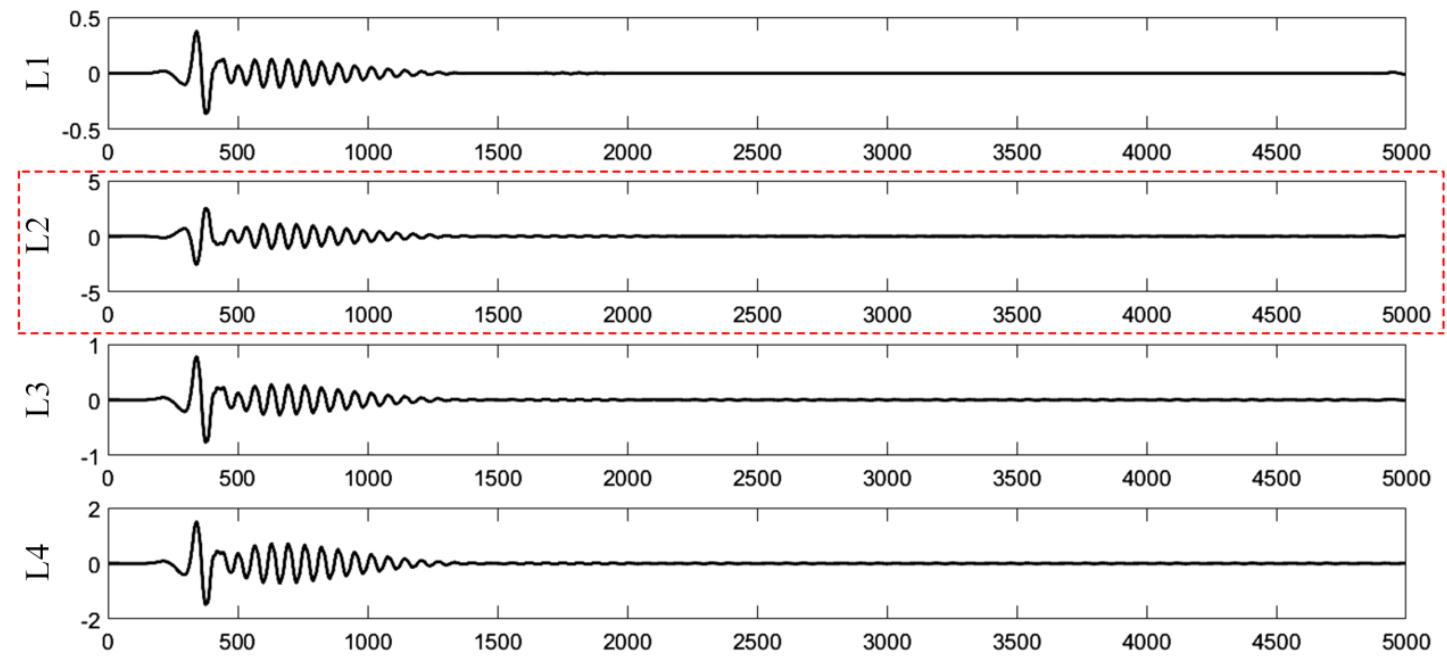

Figure 7. 6-level detail signals $\mathrm{D}_{6}$ of four feeders’ zero-sequence current (case 1)
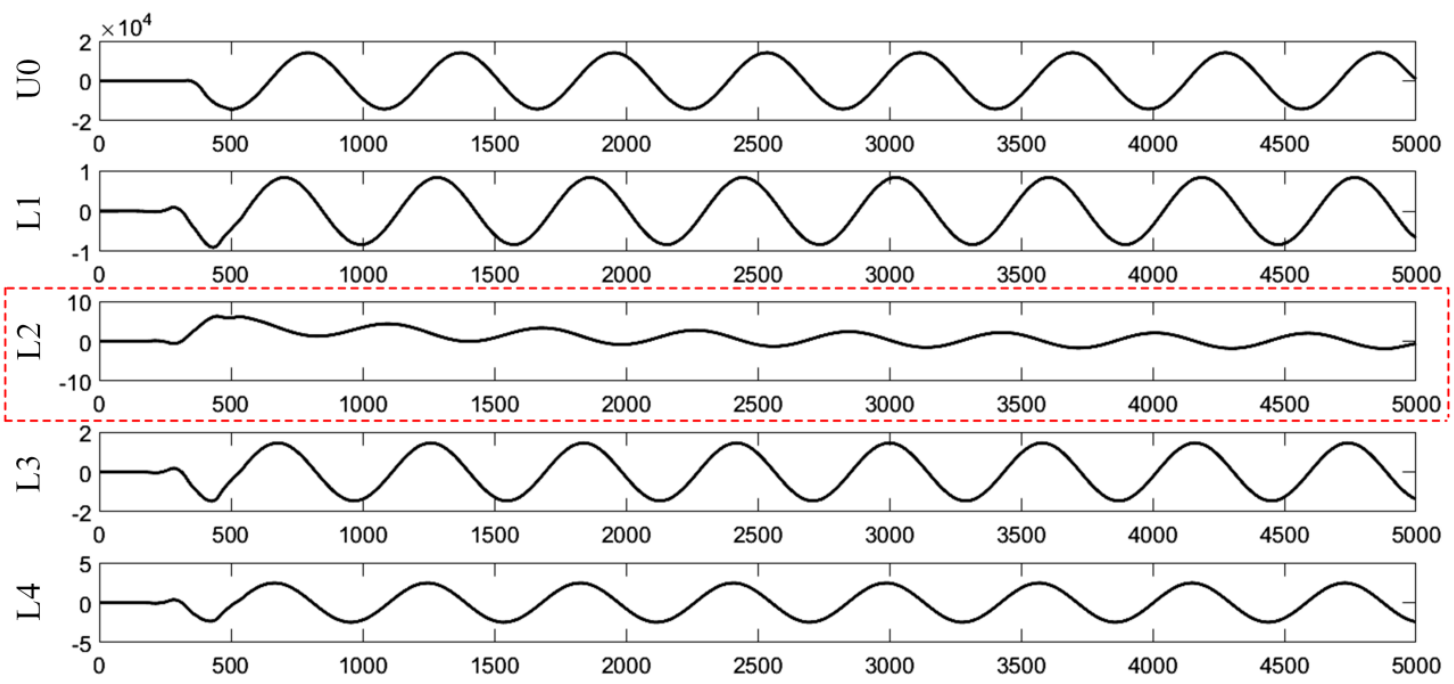

Figure 8. 6-level approximate signals $\mathrm{A}_{6}$ of four feeders' zero-sequence current and bus' zero-sequence voltage (case 1) 
As shown in Figure 7, according to the transient component criterion established in Section 3 , the $\mathrm{D}_{6}$ of feeder 2's zero-sequence current has the opposite polarity and the biggest magnitude, therefore the feeder which is selected by the transient component criterion is feeder 2 .

As shown in Figure 8, according to the steady component criterion established in Section 3, the angle difference that the $\mathrm{A}_{6}$ of feeder 2's zero-sequence current leads the $A_{6}$ of bus's zero-sequence voltage is greater than $90^{\circ}$, which means the admittance angle of feeder 2 is greater than $90^{\circ}$. Therefore the feeder which is selected by the steady component criterion is feeder 2 as well.

In summary, according to the double criteria feederselection method in Section $3, \mathrm{X}=\mathrm{Y}$ is true, feeder 2 should be broke off.

Broke off feeder 2 at 0.08 s and the zero-sequence voltage of bus gradually decreased to 0 , which means the fault disappeared, as shown in Figure 9. Therefore, the fault feeder-selection result is correct.

\subsection{Case 2}

Re-choose a feeder to be the fault feeder of single-phase ground fault, other settings are the same as case 1 .
The 6-level detail signal $\mathrm{D}_{6}$ of each feeder's zero-sequence current is shown in Figure 10, while the 6-level approximate signal $A_{6}$ of each feeder's zero-sequence current and the bus's zero-sequence voltage is shown in Figure 11.

As shown in Figure 10, according to the transient component criterion established in Section 3 , the $D_{6}$ of feeder 4's zero-sequence current has the opposite polarity and the biggest magnitude, therefore the feeder which is selected by the transient component criterion is feeder 4.

As shown in Figure 11, according to the steady component criterion established in Section 3, the angle difference that the $A_{6}$ of feeder 4's zero-sequence current leads the $A_{6}$ of bus's zero-sequence voltage is greater than $90^{\circ}$, which means the admittance angle of feeder 4 is greater than $90^{\circ}$. Therefore the feeder which is selected by the steady component criterion is feeder 4 as well.

In summary, according to the double criteria feederselection method in Section $3, \mathrm{X}=\mathrm{Y}$ is true, feeder 4 should be broke off.

Broke off feeder 4 at $0.08 \mathrm{~s}$ and the zero-sequence voltage of bus gradually decreased to 0 , which means the fault disappeared, as shown in Figure 12. Therefore, the fault feeder-selection result is correct.

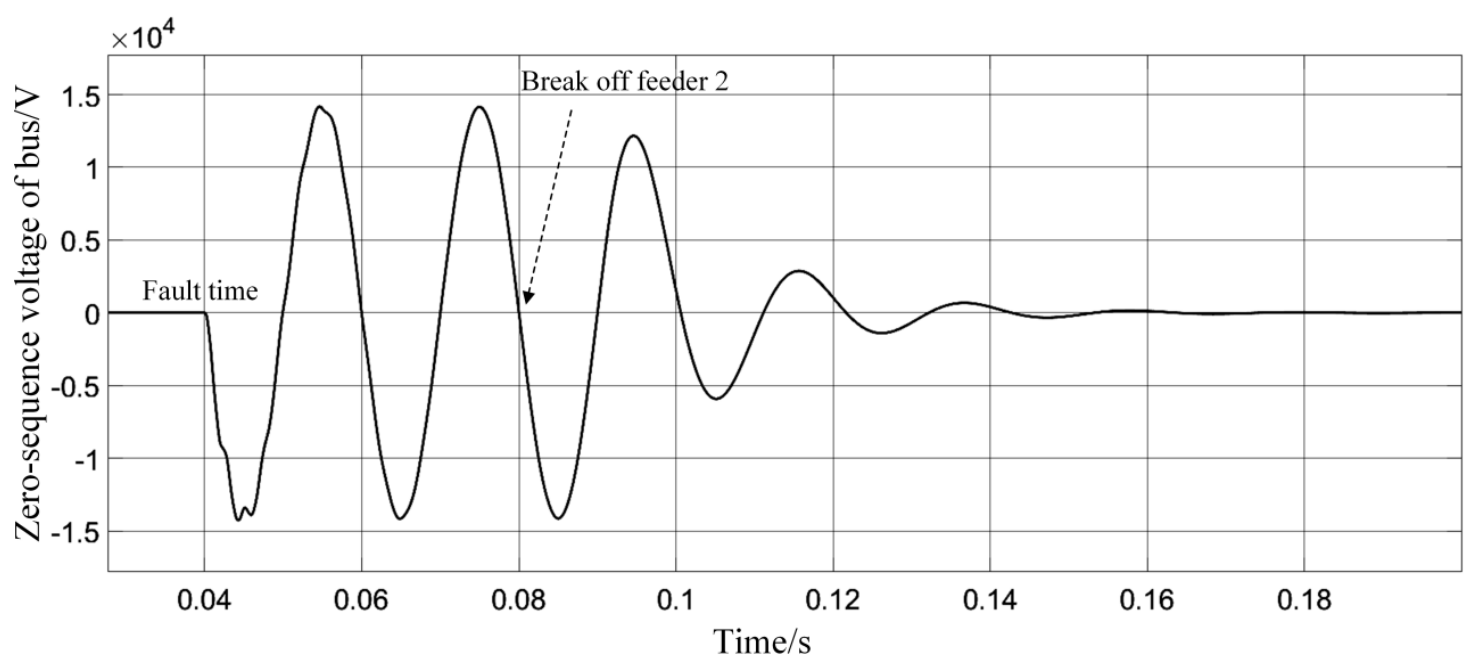

Figure 9. The zero-sequence voltage of bus when feeder 2 is broke off at 0.08 s (case 1 )

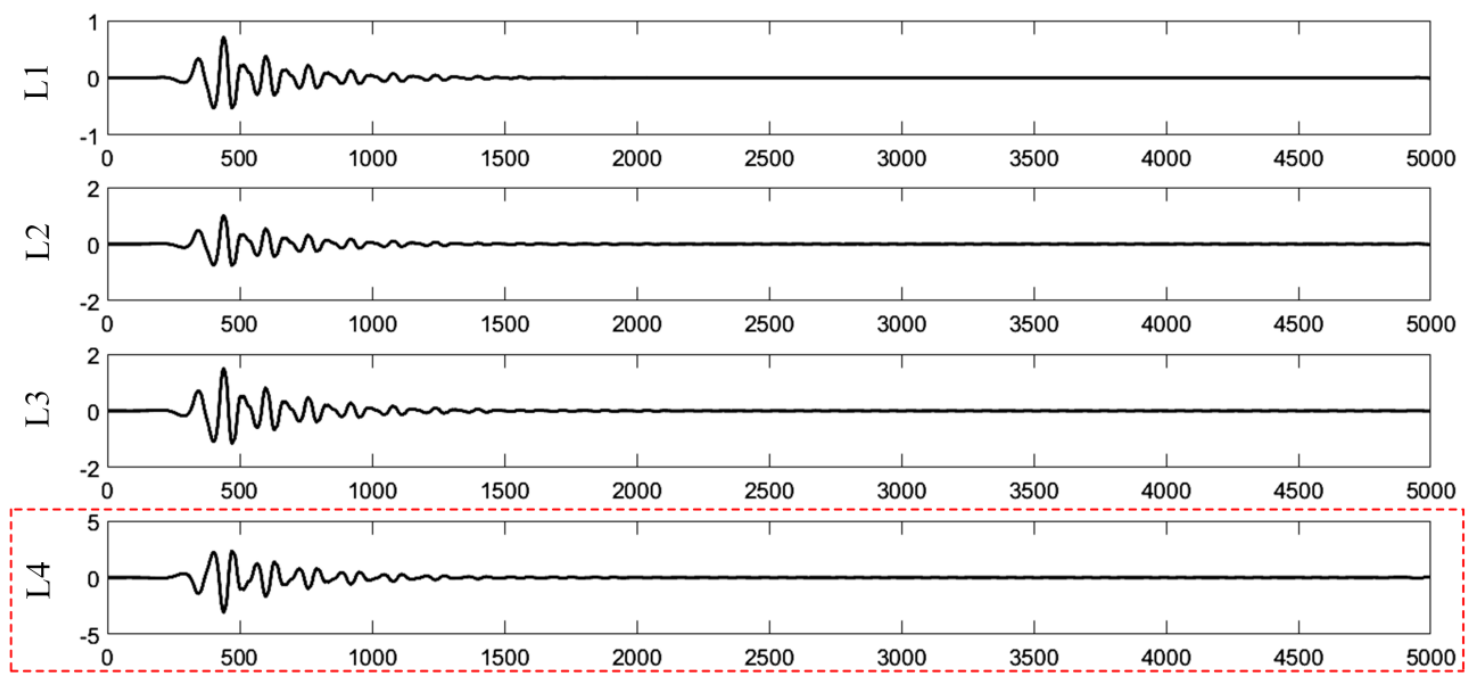

Figure 10. 6-level detail signals $\mathrm{D}_{6}$ of four feeders' zero-sequence current (case 2) 


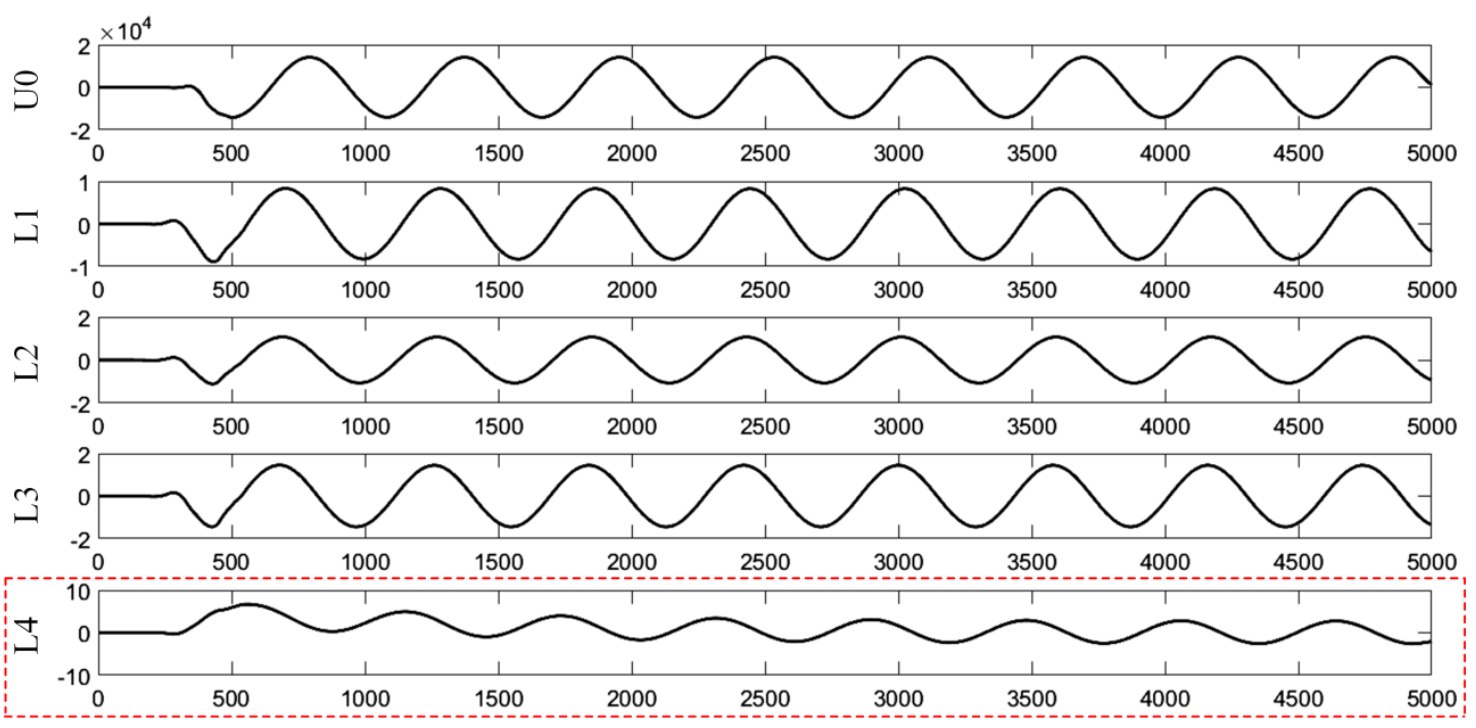

Figure 11. 6-level approximate signals $\mathrm{A}_{6}$ of four feeders' zero-sequence current and bus' zero-sequence voltage (case 2)

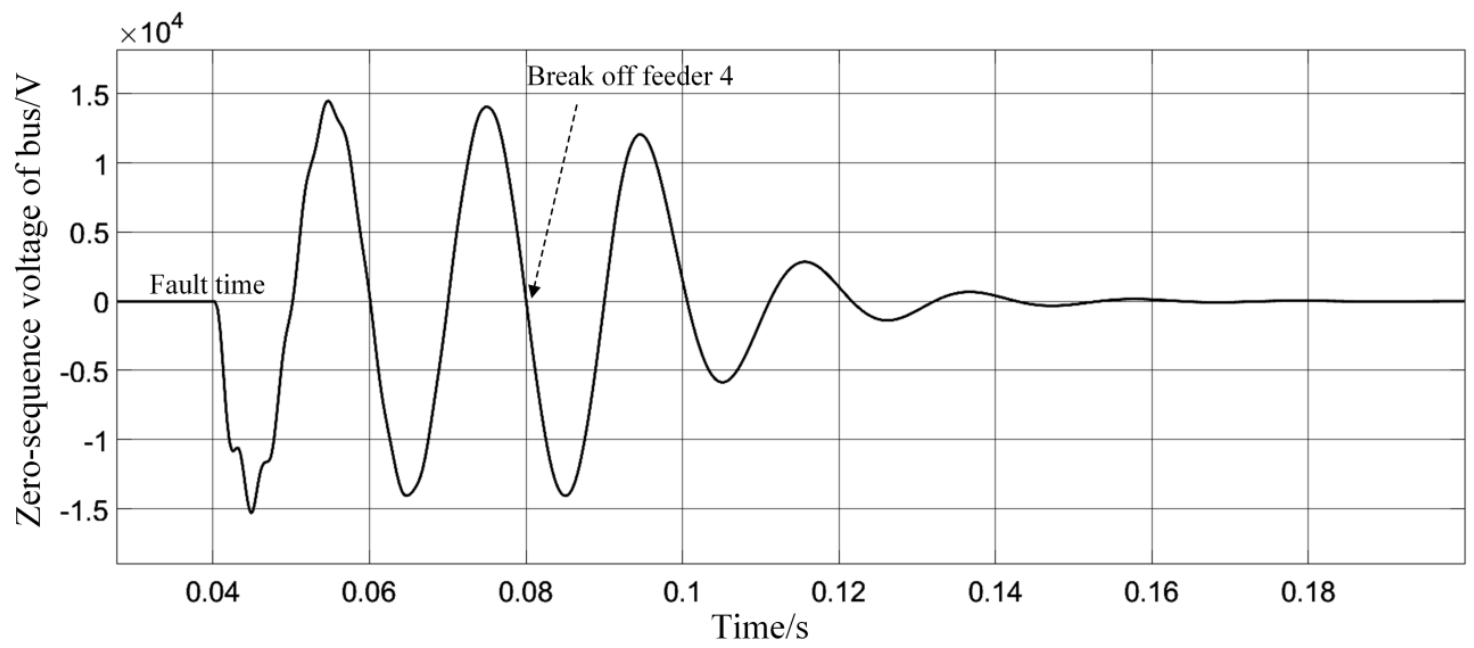

Figure 12. The zero-sequence voltage of bus when feeder 4 is broke off at $0.08 \mathrm{~s}$ (case 2)

\section{Conclusion}

The feeder-selection technology of single-phase ground fault is very important to the safe and reliable operation of resonant grounding system. In this paper, this topic is researched deeply, and the main contributions are as follows:

(1) The electrical quantity changes after the single-phase ground fault of small current grounded system are analyzed, and the reason why the amplitude/phase comparison method of zero-sequence current is not suitable to be used in resonant grounding system is summarized.

(2) Based on zero-sequence current's multi-state components (transient component and steady component), a double criteria feeder-selection method, which not only can be applied in the single-phase ground fault of resonant grounding system but also has high reliability is proposed.

However, the simulation cases conducted in this paper are relatively simple, which cannot reflect the complex characteristics of actual distribution network very well, this point needs further improvement in the future.

\section{Acknowledgements}

This research was supported by NSF of China (51607093), NSF of Jiangsu Province (BK20141452), Program of Natural Science Research of Jiangsu Higher Education Institutions of China (14KJB470006), and High level talents in Nanjing Normal University research startup research project (2014111XGQ0078).

\section{References}

[1] Shu YS., Ma LL. and Yu PJ., "Feasibility analysis of tripping in small current grounding system," in 3rd International Conference on Mechanical and Electronics Engineering, Trans Tech Publications, 4240-4244.

[2] Yang R., Yu H. and Qiu J., "Influence of damping resistance in resonant grounding system of distribution network," in 2012 China International Conference on Electricity Distribution, IEEE Computer Society, 1-3.

[3] Songsiri S. and Sirisumrannukul S., "Practical mitigation of voltage sag by resonant grounding in distribution systems: Case study of Provincial Electricity Authority," in 2011 International Conference on Material Science and Information Technology, Trans Tech Publications, 3974-3979. 
[4] Zhang X., Xu B. and Pan Z., "Study on faulty feeder selection methods of single-phase earthed fault in non-solidly grounded systems," in 42nd International Universities Power Engineering Conference, Technological Educational Institute, 480-485.

[5] Wang ZP., Liu J. and Luo WH., "Transient component-based distribution network single-phase ground fault location," in 2013 International Conference on Renewable Energy and Environmental Technology, Trans Tech Publications, 2498-2502.

[6] Xue Y., Chen X., Song H. and Xu B., "Resonance analysis and faulty feeder identification of high-impedance faults in a resonant grounding system," IEEE Transactions on Power Delivery, 32 (3). 1545-1555. Jun.2017.

[7] Xiao B., Shu H. and Gao F., "Survey of the methods of fault line selection for single phase to earth fault in networks with ungrounded neutral," Relay, 29 (4). 16-20. Apr.2001.
[8] Cheng L. and Chen Q., "A survey on faulty line selection technology for single-phase grounded transmission line in small current neutral grounded system," Power System Technology, 33 (18). 219-224. Oct.2009.

[9] Yuan GS. and Geng LQ., "ECG signal denoising algorithm based on optimization wavelet transform," in 2013 3rd International Conference on Mechatronics and Intelligent Materials, Trans Tech Publications, 785-788.

[10] Lemke C., Schuck AJ., Antoine JP. and Sima DM., "Metabolitesensitive analysis of magnetic resonance spectroscopic signals using the continuous wavelet transform," Measurement Science \& Technology, 22 (11). 114013-114013. Nov.2011. 